\title{
Correction to: A microstructural insight into the hygro- mechanical behaviour of a stabilised hypercompacted earth
}

\author{
Agostino Walter Bruno 1 - Céline Perlot · Joao Mendes $\cdot$ Domenico Gallipoli
}

Published online: 27 March 2019

(C) RILEM 2019

Correction to: Materials and Structures (2018) 51:32

https://doi.org/10.1617/s11527-018-1160-9

The article A microstructural insight into the hygromechanical behaviour of a stabilised hypercompacted earth, written by Agostino Walter Bruno, Céline Perlot, Joao Mendes and Domenico Gallipoli, was originally published online without Open Access. After publication in volume 51, article ID 32 RILEM decided to grant the author to opt for open choice and to make the article an open-access publication. Therefore, the copyright of the article has been changed to (c) The Author(s) 2018 and the article is forthwith distributed under the terms of the Creative Commons Attribution 4.0 International License (http://creativecommons.org/licenses/by/4.0/), which permits use, duplication, adaptation, distribution and reproduction in any medium or format, as long as you give appropriate credit to the original author(s) and the source, provide a link to the Creative Commons license, and indicate if changes were made.

Publisher's Note Publisher's Note Springer Nature remains neutral with regard to jurisdictional claims in published maps and institutional affiliations.
The original article can be found online at https://doi.org/10.1617/s11527-018-1160-9.
A. W. Bruno $(\square) \cdot$ C. Perlot · D. Gallipoli Laboratoire SIAME - Bâtiment ISABTP, Fédération IPRA, EA4581, Université de Pau et des Pays de 1'Adour, Allée du Parc Montaury, 64600 Anglet, France e-mail: agostinowalter.bruno@univ-pau.fr

J. Mendes

Department of Mechanical and Civil Engineering,

Northumbria University, Newcastle upon Tyne, UK 